\title{
Riqueza movida a petróleo: maldição ou alavanca para o desenvolvimento?
}

\section{Wealth driven by the oil industry: a curse or a lever for development?}

Marlúcia Junger Lumbreras - Doutora em Planejamento Urbano e Regional, pela Universidade Candido Mendes (UCAM). Professora do Instituto Federal de Educação, Ciência e Tecnologia Fluminense (IFF). E-mail: mjlumbreras@gmail.com

Rosélia Piquet - Doutora em Teoria Econômica, pela Universidade Federal do Rio de Janeiro (UFRJ). Professora da UFRJ. Professora e coordenadora do Doutorado em Planejamento Regional e Gestão da Cidade da Universidade Candido Mendes (UCAM). E-mail: ropiquet@terra.com.br

\section{Resumo}

O propósito do presente artigo é investigar a utilização de políticas industriais para o fomento do desenvolvimento, para o setor petrolífero, por meio da discussão da utilização de Políticas de Conteúdo Local (PCL). Trata-se de uma análise qualitativa baseada em pesquisa bibliográfica e documental, donde pôde-se perceber que paísesprodutores de petróleo e gás, independentemente de seus estágios de desenvolvimento, buscam aplicar tais políticas com $\mathrm{O}$ intuito de fortalecer a indústria local, gerar empregos e desenvolver tecnologia. Contudo, os países subdesenvolvidos e em desenvolvimento enfrentam dificuldades em sua implantação.

\section{Palavra-chave}

Política de Conteúdo Local. Petróleo. Maldição dos Recursos Naturais. Política Industrial. Desenvolvimento.

\begin{abstract}
The purpose of this article is to investigate the implementation of industrial policies to promote oil industry development by discussing the application of Local Content Policies (LCP). It is a qualitative analysis based on bibliographical and documentary research, in which it can be seen that oil and gas producing countries, regardless of the stage of development, seek to apply such policies in order to strengthen local industry, generate jobs and develop technology. However, underdeveloped and developing countries have more difficulties in implementing LCP.
\end{abstract}

\section{Keywords}

Local Content Policy. Oil. Natural Resource Curse. Industrial Policy. Development. 


\section{INTRODUÇÃO}

A adoção de políticas industriais ganha proeminência após a Segunda Guerra Mundial, quando os países adotaram vasta gama de medidascom o intuito de diversificar os setores produtivos. Nos países latino-americanos, prevaleceu a concepção desenvolvimentista do Estado enquanto promotor de políticas industriais, entendendo que o objetivo das mesmas seria "a promoção da atividade produtiva, na direção de estágios de desenvolvimento superiores aos preexistentes em um determinado espaço nacional" (FERRAZ; PAULA; KUPFER, 2013, p. 313). Deste modo, as políticas industriais na América Latina, até a década de 1980, tiveram como foco criar novos setores voltados à diversificação das respectivas estruturas econômicas, dado o alto grau de especialização na exportação de recursos naturais (CEPAL, 2012).

Porém, após o Consenso de Washington, em 1989, prevaleceram as orientações dos organismos internacionais, tais como o Fundo Monetário Internacional (FMI) e o Banco Mundial, argumentando que os riscos associados às tentativas de corrigir as falhas de mercado por meio de políticas públicas eram elevados, sendo mais seguro se abster da intervenção, momento em que muitos países começaram a desfazer suas políticas industriais (TORDO et al., 2013). Cabe ressaltar que, apesar de as nações desenvolvidas defenderem a liberalização econômica como a melhor maneira de fomento ao crescimento econômico e ao bem-estar social, a maior parte delas implantam políticas industriais (FERRAZ; PAULA; KUPFER, 2013). Inclusive, Nester (1997 apud LIN; MONGA, 2013) salienta que a posição competitiva de cada empresa norte-americana é afetada pela política do governo, e que sua grande indústria é extremamente envolvida e dependente do mesmo.

Além disso, os países que adotaram como estratégia em sua política de desenvolvimento empregar os recursos advindos de exportações, para viabilizar mudanças estruturais em benefício de setores produtivos mais sofisticados, obtiveram melhoria na restrição externa e nodesempenho em termos de crescimento (LOURENÇO; CARDOSO, 2018).

Deste modo, o desenvolvimento de setores produtivos independentes de recursos naturais tem sido mais urgente para países produtores dos mesmos, incluindo os exportadores de Petróleo e Gás Natural (P\&G), em virtude da recente tendência de "comoditização" do comércio mundial (TORDO et al., 2013). Tal tendência tem reforçado as discussões sobre o papel do petróleo no desenvolvimento, visto que os países que apenas exportam petróleo bruto não se beneficiam de tal riqueza, sendo necessária a construção de uma rede de 
empresasfornecedoras de bens, serviços e tecnologia, para que se apropriem da riqueza proveniente do recurso natural.

Isto posto, o propósito do presente artigoé investigar a utilização de políticas industriais para o fomento do desenvolvimento, notadamente por meio da discussão da adoção de Políticas de Conteúdo Local (PCL), apresentando as principais mudanças em curso nesta política no Brasil, bem como relacioná-la com asadotadas por outros países. Trata-se de uma análise qualitativa baseada em: (i) pesquisa bibliográfica, consulta a livros e periódicos indexados em diversas bases, notadamente nas bases Scopus e Science Direct, e (ii) documental, por meio de consulta à Agência Nacional do Petróleo, Gás Natural e Biocombustíveis (ANP), à Comissão Econômica para a América Latina e o Caribe (CEPAL), ao Instituto de Pesquisa Econômica e Aplicada (IPEA), ao Instituto Brasileiro de Petróleo, Gás e Biocombustíveis (IBP), à Petrobras e ao Banco Mundial.

\section{MALDIÇÃO DOS RECURSOS NATURAIS E DOENÇA HOLANDESA}

Quando se analisavam as oportunidades de desenvolvimento de um país, até o início do século $\mathrm{XX}$, os recursos naturais assumiam relevância (HIRSCHMAN, 1961).Contudo, Celso Furtado, em 1957, já afirmava que “o desenvolvimento não é uma fatalidade: já indicamos que a estagnação é uma solução para os problemas que atualmente estão se acumulando" (FURTADO, [1957] 2008, p. 61). E, ao findar o mesmo século, passou-se a questionar se possuir grandes reservas naturais constituíam dádiva ou maldição (ENRÍQUEZ, 2007).

Sachs e Warner (1995) estudaram uma amostra de 95 países em desenvolvimento, entre 1970-1990. O ponto da partida da pesquisa foi a análise do percentual do PIB representado pelas exportações baseadas em recursos agricultura, minerais e combustíveis. A partir daí, avaliaram o crescimento do PIB dos países estudados durante os 20 anos seguintes e concluíram que as economias pobres em recursos naturais geralmente superam as economias ricas em recursos no que tange ao crescimento econômico. Tal fenômeno ficou conhecido na literatura como a maldição dos recursos naturais.

Contudo, os autores alertam que, embora tenham encontrado evidências de uma relação negativa entre a intensidade dos recursos naturais e o crescimento subsequente, seria um erro concluir que os países deveriam subsidiar ou proteger os demais setores da economia, pois o estudo não é definitivo, existem outras políticas que podem ser adotadas para elevar as taxas de crescimento nacional, e os resultados relacionados ao bem-estar da abundância de recursos podem 
ser bem diferentes das implicações de crescimento. Deste modo, consideram que a questão de políticas apropriadas orientadas para o crescimento, nos países em desenvolvimento, ricos em recursos naturais, é um tópico aberto, sendo importante análises mais aprofundadas (SACHS; WARNER, 1995).

Há países,entretanto,que dispõem de fartos recursos naturais e alcançaram elevados índices de crescimento e desenvolvimento, mesmo tendo abundantes recursos - tais como: Austrália, Estados Unidos, Islândia, Noruega e Canadá. Tal fato suscitou uma série de críticas aos estudos de Sachs e Warner (1995), podendose citar Brunnschweiler (2008), que, ao utilizar indicadores desenvolvidos pelo Banco Mundial - que estimam o capital natural per capita, bem como a riqueza mineral per capita - para testar seu efeito no crescimento econômico no período de 1970 a 2000 e compará-los com os resultados obtidos por aqueles autores, mostrou que os recursos naturais e, em particular, os recursos minerais têm uma associação direta positiva com o crescimento real do PIB para o período analisado.

Além disso, a mesma Brunnschweiler (2008) verificou a importância da qualidade institucional no processo de crescimento e desenvolvimento econômico ao examinar aspectos institucionais importantes, como o estado de direito e a corrupção, assim como a competência do Estado e, particularmente, a burocracia e sua interação com as medidas de abundância de recursos. Depois, investigou a possibilidade de que a abundância de recursos naturais afete negativamente as instituições.

As análises mostraram não haver evidências de que a abundância de recursos afete negativamente a qualidade institucional, contradizendo a hipótese de uma maldição indireta dos recursos naturais (BRUNNSCHWEILER, 2008).

Por seu turno, Corden e Neary (1982) investigaram um fenômeno denominado doença holandesa, que ocorre em países desenvolvidos e em desenvolvimento, caracterizado pela existência, em um mesmo país, de setores da economia em plena expansão - como os setores de natureza extrativista ou setores industriais, que envolvem atividades tecnologicamente avançadas - e setores em declínio - os setores tradicionais existentes antes da exploração de recursos naturais ou setores industriais mais antigos.

O estudo analisou os efeitos advindos de uma expansão rápida e abrangente de um setor da economia sobre a alocação de recursos, a distribuição de renda dos fatores e a taxa de câmbio real. Os pesquisadores observaram que, no modelo mais simples considerado - onde assumiram que somente a mãodeobra era móvel entre os setores -, houve desindustrialização e um aumento no preço 
relativo de bens nãonegociados em relação aos bens comercializados. No entanto, ao estudar outros modelos, que permitiam mobilidade intersetorial de mais de um fator, foi demonstrado que alguns desses desfechos poderiam ser revertidos (CORDEN; NEARY, 1982).

Bresser-Pereira, Marconi e Oreiro (2016) também estudaram a doença holandesa, e a definem como:

[...] a crônica sobreapreciação da taxa de câmbio de um país causada pela exploração de recursos abundantes e baratos, cuja produção e exportação é compatível com uma taxa de câmbio claramente mais apreciada que a taxa de câmbio que torna competitivas internacionalmente as demais empresas de bens comercializáveis que usam a tecnologia mais moderna existente no mundo (BRESSER-PEREIRA; MARCONI; OREIRO, 2016, p. 69).

Para os referidos autores, a doença holandesa é uma falha de mercado que afeta todos os países em desenvolvimento e impede que outros setores da economia se desenvolvam, mesmo que os bens produzidos utilizem tecnologia de ponta, pois não serão competitivos, visto que, além da taxa de câmbio vigente, haverá duas taxas de câmbio de equilíbrio - a taxa de câmbio de equilíbrio corrente $^{1}$ e a taxa de câmbio de equilíbrio industrial ${ }^{2}$.

Bresser-Pereira, Marconi e Oreiro (2016) apontam que, para neutralizar os efeitos da doença holandesa, seria necessário estipular um imposto que equalizasse o preço das commodities ao preço das demais mercadorias, porém, evitando crescer com déficit em conta corrente ou poupança externa. E ressaltam que, quando um país consegue neutralizar a doença holandesa e se industrializar, ele consegue também neutralizar a maldição dos recursos naturais.

Entretanto, Hirschman (2008) destaca que os efeitos fiscais impactam vigorosamente as atividades petrolíferas e de mineração que apresentam as características do enclave - ausência de envolvimento com o restante da economia -, e que o efeito de repercussão fiscal depende da agilidade e da habilidade dos governos nacionais em requerer uma participação nos lucros ou em taxar as operações de mineração.

Deste modo, sendo a doença holandesa uma falha de mercado, abrese espaço para a intervenção do Estado buscando atenuar seus efeitos, sendo por meio de taxação ou implantando outras estratégias, podendo-se destacar a utilização de políticas industriais.

\footnotetext{
Taxa de câmbio para a qual o mercado deveria convergir na ausência de outros fatores interferindo no mercado.

2 Taxa que possibilita a competitividade das empresas produtoras de bens e serviços comercializáveis internacionalmente.
} 


\section{POLÍTICA INDUSTRIAL}

As políticas governamentais intervencionistas e a criação de empresas estatais, que vigoraram durante as décadas de 1960 e 1970 em muitos países em desenvolvimento, foram motivadas pela escassez de empreendedores privados; pela dificuldade de financiamento privado local para novos empreendimentos ou para a expansão dos antigos; pela incapacidade das empresas assumirem os riscos de investimentos em larga escala; pelo medo de exploração por firmas estrangeiras; e pelas correntes intelectuais que enfatizavam as limitações dos mercados (STIGLITZ; LIN; MONGA, 2013).

No Brasil, a criação de importantes empresas estatais teve início ainda na década de 1940, destacando-se: Companhia Siderúrgica Nacional (CSN) (1941), Companhia Vale do Rio Doce (CVRD) (1942), Banco Nacional de Desenvolvimento Econômico (BNDE) (1952); Petróleo Brasileiro S.A. (Petrobras) (1953) e Furnas Centrais Elétricas S. A. (Furnas) (1957).

Contudo, o resultado obtido a partir da adoção de políticas industriais é heterogêneo. Há países que conseguiram registrar altas taxas de crescimento e outros que permaneceram estagnados, ou até regrediram. Porém, vale ressaltar que, embora as políticas industriais fossem frequentemente responsabilizadas pelos resultados decepcionantes, muitas vezes, a verdadeira fonte do problema estava nos fracassos nas políticas macroeconômicas e na governança (STIGLITZ; LIN; MONGA, 2013).

No que tange ao Brasil, até a década de 1970, o país implantou uma ativa e forte política industrial voltada para a substituição de importações, sendo bemsucedida na estruturação de novos setores, como petroquímica e papel e celulose, mas não conseguiu impulsionar setores preexistentes, como têxteis e automotivos. Contudo, após a década de 1980, devido principalmente às dificuldades macroeconômicas decorrentes de níveis muito elevados de endividamento interno e externo, a política industrial foi progressivamente desmontada e praticamente abandonada (KUPFER; FERRAZ; MARQUES, 2013).

Após o Consenso de Washington, com a ascensão do fundamentalismo de mercado, o pêndulo passou de falhas de mercado a falhas de governo. $\mathrm{O}$ novo evangelho intelectual para a economia do desenvolvimento estava fundamentado na racionalidade dos agentes que operavam nos mercados livres e atribuía o sucesso econômico apenas à liberalização, à privatização e à desregulamentação. Tornou-se moda rejeitar qualquer tentativa proativa do governo de promover a transformação estrutural, e a política industrial ficou em segundo plano (STIGLITZ; LIN; MONGA, 2013). 
Neste contexto, ao assumir o governo do país, em 1995, Fernando Henrique Cardoso (FHC), apoiando-se na hegemonia do neoliberalismo em escala mundial, redireciona o Brasil de forma a introduzir uma nova ordem centrada no primado do mercado com o objetivo de superar a herança do nacional-desenvolvimentismo (DINIZ, 2011; SCHUTTE, 2016), e intensifica o processo de privatização de empresas estatais iniciado no governo Collor, dentre elas a Companhia Vale do Rio Doce.

Tal posicionamento suscitou importantes debates e manifestações contrárias às privatizações, notadamente da Petrobras. Portanto, para conseguir a aprovação da Emenda Constitucional nº 6, de 15 de agosto de 1995 (BRASIL, 1995), determinando o fim da exclusividade da Petrobras no exercício do monopólio da União na exploração e produção de petróleo, e aprovar o regime de concessões, FHC teve que assumir o compromisso de não privatizar a empresa.

Porém, de acordo com Ribeiro e Novaes (2014), foram adotadas estratégias de "privatização disfarçada" por meiodo aumento da participação privada na composição do capital social da Petrobras e da segmentação da empresa em unidades de negócio, permitindo assim sua venda em fatias menores, causando menor alarde do que a privatização.

Entretanto, a crise global de 2008-2009 impeliu economistas e formuladores de políticas a reconhecer que as falhas de mercado são generalizadas, que alguns dos principais objetivos políticos nacionais e globais - igualdade de oportunidades para todos os cidadãos, controle da poluição, mudança climática, entre outros simplesmente não são refletidos em valores de mercado. Além disso, mesmo os governos que defendem políticas horizontais ou neutras acabam agindo de modo a favorecer certas indústrias mais do que a outras; portanto, moldam a alocação setorial da economia. Desta forma, há um novo ímpeto para a política industrial e o reconhecimento geral - mesmo entre os economistas tradicionais - de que ela geralmente envolve uma boa política econômica (STIGLITZ; LIN; MONGA, 2013).

Seguindo tal tendência, a política industrial voltou a ter importância no Brasil, nos anos 2000, destacando-se a implantação de três políticas:

- a Política Industrial, Tecnológica e de Comércio Exterior (PITCE), de 2004 a 2007: concebida para atender a setores com grandes e crescentes déficits comerciais (bens de capital, semicondutores, software, bem como fármacos e medicamentos);

- a Política de Desenvolvimento Produtivo (PDP), de 2008 a 2010: idealizada dentro de um contexto de crescimento internacional e abundância de moeda estrangeira decorrente de melhorias nos termos de troca, com o objetivo de alavancar investimentos e inovação para sustentar o crescimento; 
- o Plano Brasil Maior (PBM), de 2011 a 2014: criado para fortalecer as operações em setores em que a inovação tecnológica desempenha papel fundamental, aumentar a produtividade e a atualização tecnológica ao longo das cadeias de valor, ampliar os mercados interno e externo para empresas brasileiras e propiciar um crescimento socialmente inclusivo e ambientalmente sustentável (KUPFER; FERRAZ; MARQUES, 2013).

Merece destaque também o Programa de Aceleração do Crescimento (PAC), criado em 2007, que representou a retomada do planejamento e a execução de grandes obras de infraestrutura social, urbana, logística e energética do país por meio de investimentos em setores estruturantes (BRASIL, 2018).

Ao longo desses quase dez anos de retorno da política industrial no Brasil, muitas vezes o foco foi desviado para a necessária gestão dos efeitos indesejáveis derivados das incertezas econômicas ocasionadas, em grande parte, pelo boom dos preços das commodities e pela crise financeira internacional (KUPFER; FERRAZ; MARQUES, 2013). Além disso, a crescente perda de competitividade internacional da indústria nacional perante outros países deriva do câmbio excessivamente valorizado, dos juros reais muito altos e da âncora fiscal destinada ao pagamento da dívida (CANO, 2012).

Neste contexto, cabe refletir sobre o papel do petróleo no desenvolvimento e sobre a adoção de PCL para o setor de P\&G.

\section{PETRÓleO E DESENVOLVIMENTO}

De acordo com a ANP (2017), o Brasil é o $10^{\circ}$ maior produtor mundial de petróleo e o maior produtor da América Latina, envolvendo 311 blocos de exploração e produção e 443 campos, geridos por 95 grupos econômicos. Além disso, a indústria de petróleo brasileira representa 11\% do PIB industrial e 50\% da oferta interna de energia.

A cadeia produtiva da indústria do petróleo apresenta atributos específicos, compreendidos em três grandes etapas:atividades de exploração, produção e transporte do petróleo extraído para as refinarias (upstream); refino, importação e exportação de petróleo, gás natural e derivados, bem comoseu transporte e armazenagem (midstream); e as tarefas de distribuição e comercialização dos derivados do petróleo (downstream). Todos os segmentos da indústria petrolífera demandam grandes investimentos, notadamente na fase de E\&P, em decorrência do alto risco que representa (PINTO JÚNIOR et al., 2016). 
Em conjunto, a indústria de petróleo apresenta grande potencial de atração de investimentos e, consequentemente, contribui para a economia do Brasil. Entretanto, os primeiros anos do século XXI foram marcados por profundas oscilações dos preços de petróleo resultantes de questões técnicas, geológicas, geopolíticas e econômicas (PINTO JÚNIOR, 2015), o que aciona questionamentos relativos à possibilidade de o país ser afetado pela chamada "maldição dos recursos naturais". Além disso, é um grande desafio transformar a riqueza natural em desenvolvimento, principalmente em um país que é referência em empreender amplos avanços econômicos ao mesmo tempo em que mantém desmensuradas desigualdades sociais, econômicas e regionais (BACELAR, 2007).

Por conseguinte, a descoberta de gigantescos reservatórios de petróleo e gás (P\&G) em águas ultraprofundas nas províncias chamadas de pré-sal, suscitou a interrupção das rodadas de licitações com a intenção de averiguar a melhor forma de aproveitar essas reservas, com interesse em requalificar o parque industrial brasileiro, envolvendo setores de máquinas, equipamentos e construção naval, bem como setores de comércio e serviços relacionados (SCHUTTE, 2016).

$\mathrm{O}$ que se pretendia era atenuar e impedir os resultados nocivos da abundância de recursos naturais por meio do estabelecimento de políticas públicas com o objetivo de evitar a sobrevalorização cambial de modo a potencializar o desenvolvimento e a diversificação industrial, que, do contrário, tenderiam a se concentrar nas atividades extrativistas (POMPERMAYER, 2011).

De acordo com Schutte (2016), o desenvolvimento baseado em abundância de recursos naturais, em países da periferia, tende a reforçar a monoprodução, portanto, carece de uma política de estado voltada à promoção do desenvolvimento, pois o mesmo não ocorrerá por meio da dinâmica espontânea do sistema econômico.

Dentre tais políticas públicas, encontra-se a Política de Conteúdo Local, que será examinada a seguir.

\subsection{A POLÍTICA DE CONTEÚDO LOCAL}

As descobertas de reservas de P\&G impulsionam os formuladores de políticas públicas, nos países produtores, a procurar obter os maiores benefícios para suas economias a partir da extração desses recursos esgotáveis (TORDO et al., 2013). Apesar de serem ricos em $P \& G$, há países que apresentam fraco desempenho econômico e têm sido tema de estudos, que buscam revelar quais as origens de tal fenômeno, assim como verificar como podem ser estabelecidas políticas públicas que sejam capazes de tornar a exploração de P\&G favorável 
aos referidos países por meio do desenvolvimento da indústria local e da redução da dependência ao recurso natural (XAVIER JÚNIOR, 2012).

Nessas circunstâncias, elaborar ou aditar uma legislação quanto à adoção de conteúdo local (CL) tornou-se uma estratégia política em países em desenvolvimento ricos em recursos, tanto naqueles que sãoprodutores maduros quanto nosmais recentes (TORDO et al., 2013). Na literatura acadêmica, existem várias definições para CL, mas a maioria dos pesquisadores coadunam com a ideia de que é um requisito, geralmente expresso como uma porcentagem dos custos, da força de trabalho local e de matérias-primas utilizadas no processo de fabricação com o intuito de criar o valor adicionado à economia local (SEMYKINA, 2017).

Todavia, as economias pouco desenvolvidas enfrentam desafios consideráveis na implantação de PCL, pois dependem de acelerar rapidamente a capacidade doméstica de oferta de serviços e suprimentos, tendo, provavelmente, dificuldade na criação de redes de serviços mais complexas. Além disso, o desafio de E\&P é agravado pelo ritmo em que as atividades do setor são realizadas, bem como pelas limitações na capacidade de fomento por parte do governo (TORDO et al., 2013). Deste modo, ao analisar a adoção de PCL nos países produtores, é fundamental levar em consideração o contexto de aplicação das mesmas, evitando comparar aquilo que é incomparável, ou seja, comparar países desenvolvidos tais como Noruega e Reino Unido - com países subdesenvolvidos - a exemplo de Angola e Nigéria.

Logo, neste artigo, pretende-se apresentar e discutir alguns modelos de regulamentação do setor petrolífero, especialmenteos referentes à PCL, considerando o contexto de sua aplicação, bem como a relevância dos mesmos para o processo de desenvolvimento do país no qual foramimplantados. Foram selecionados dois países da Europa - Reino Unido e Noruega -, dois países situados na África - Nigéria e Angola - e dois países localizados na América do Sul - Venezuela e Brasil.

O modelo praticado na Noruega é frequentemente citado como um caso de sucesso. Nilsen (2016), ao estudar a PCL norueguesa, verificou que, nos primórdios da história do petróleo norueguês, o Estado desenvolveu uma PCL rigorosa com o intuito de garantir que suas próprias empresas pudessem participar e liderar operações no longo prazo. Ou seja, a Noruega decidiu desenvolver seus recursos petrolíferos lentamente, com o objetivo explícito de permitir que um setor de serviços noruegueses se desenvolvesse (TORDO et al., 2013). Tal estratégia logrou enorme sucesso e permitiu a formaçãode uma indústria altamente competitiva, composta porempresas líderes mundiais em 
exploração submarina, perfuração e engenharia, o que permitiu ao Estado, promover posteriormente a liberalização no setor (NILSEN, 2016).

Em 2009, quando a atividade petrolífera se estendeu geograficamente para o extremo norte da Noruega, o Ministério do Petróleo e Energia formulou documentos com o intuito de, mais uma vez, regular a atividade e fomentar a participação de empresas locais na exploração e produção de petróleo na referida região. Como não foram estipulados índices de CL específicos, as empresas tiveram que dialogar entre si e também com os representantes locais - empresários regionais, associações de empresas regionais e organizações trabalhistas -, procurando soluções que atendessem às expectativasrelacionadas aos benefícios do CL. Ou seja, o Estado norueguês ainda administra e controla as operações (NILSEN, 2016).

A experiência do Reino Unidono setor de petróleo é bem diversa. Quando iniciou sua trajetória no setor, já possuía um parque industrial estruturado em um nível mais avançado do que o da Noruega, e optou por uma abordagem baseada no mercado (TORDO et al., 2013), preferindo o desenvolvimento mais rápido de seus recursos no Mar do Norte, confiando no serviço de empresas estrangeiras e nos efeitos indiretos de sua participação no mercado (HALLWOOD, 1990 apud TORDO et al., 2013). Os blocos foram concedidos discricionariamente, sem a realização de leilões, geralmente às empresas compromissadas com o rápido desenvolvimento das reservas e com o uso de fornecedores baseados no Reino Unido. Contudo, a partir da década de 1970, houve uma revisão de tais políticas em virtude da descoberta de dois grandes campos petrolíferos; do primeiro choque do petróleo; e da insuficiente participação das firmas britânicas no fornecimento de bens e serviços para a indústria petrolífera (XAVIER JÚNIOR, 2012). Assim, passou a ser implantada uma PCL que não previa sanções às concessionárias - apesar de companhias com nível baixo de CL terem pouca probabilidade de ganhar novas concessões -, mas era pautada no apoio às empresas domésticas do setor parapetrolífero, no financiamento aos fornecedores locais e na supervisão de compras das empresas petrolíferas (XAVIER JÚNIOR, 2012; TORDO et al., 2013).

Observa-se que os dois países desenvolvidos citados acima, Noruega e Reino Unido, adotaram métodos de exigência de CL diferentes, porém ambos utilizaram tal instrumento com o intuito de se apropriar das rendas petrolíferas para o desenvolvimento e fortalecimento de sua própria indústria.

O diferencial em termos de desenvolvimento econômico, tecnológico e social entre os exemplos anteriores e os países africanos indica, desde logo, que as experiências seriam profundamente diferenciadas. Ovadia (2016), ao estudar a utilização de PCL em países da região subsaariana, destaca que há uma longa 
história de tentativas fracassadas de promover o controle nacional de recursos petrolíferos na África, sendo que talcontrole somente ganhou impulso na década de 1970, quando os países começaram a ter suas próprias empresas nacionais.

O governo nigeriano criou sua empresa em 1977 - Nigerian National Petroleum Corporation (NNPC) - e iniciou um programa de nacionalização. Contudo, tal processo foi amargamente dificultado pelo capital estrangeiro, e as políticas implantadas não conseguiram dar ao Estado nigeriano controle efetivo sobre a indústria que ficaram restritas à captura das rendas do petróleo pelas elites. Todavia, no começo do século XXI, a Nigéria introduziu ações para a adoção de exigências de CL por meio da criação de uma divisão de CL dentro da NNPC e da promulgação da Lei de Desenvolvimento de Conteúdo da Indústria de Petróleo e Gás da Nigéria, estabelecendo metas para a participação nigeriana em 280 categorias separadas sobre serviços de petróleo (OVADIA, 2016).

Quanto a Angola, após sua independência, em 1975, o governo angolano nacionalizou a empresa portuguesa ANGOL de Lubrificantes e Combustíveis, criando a companhia nacional de petróleo Sociedade Nacional de Combustíveis (Sonangol). As empresas internacionais foram autorizadas a operar em Angola em joint ventures e acordos de contratação com a Sonangol; e, a partir da década de 1980, foram aprovadas leis que estabeleceram metas quanto aos angolanos serem contratados por empresas internacionais e instituiu-se um quadro obrigatório para a formação e promoção dos funcionários angolanos. No entanto, essas leis e regulamentos foram largamente ignorados pelas companhias estrangeiras (OVADIA, 2012 apud OVADIA, 2016).

Apesar de a Sonangol ser a principal instituição de implantação da PCL em Angola, não é a única. O Ministério do Petróleo criou uma diretoria chamada Direção Nacional de Fomento à Angolanização para aumentar a participação angolana no setor petrolífero. Foram aprovadas novas leis que fornecem incentivos fiscais às empresas locais, bem como leis e regulamentos que exigem o uso de bancos angolanos e obrigam as companhias de petróleo a pagar impostos e empreiteiros locais em moeda angolana (OVADIA, 2016).

No entanto, ainda de acordo com Ovadia (2016), particularmente após o choque do preço do petróleo, em 2014, as empresas estrangeiras vêm pressionando os governos africanos a reduzirem os índices de CL, alegando necessidade de reduzir custos, forçando o enfraquecimento dessas políticas em favor de uma agenda mais pró-businesse suscitando dúvidas quanto aos benefícios das mudanças para o desenvolvimento nacional.

Nota-se que os dois países africanos têm tido muito mais dificuldades em aplicar uma PCL, bem como se apropriar dos benefícios advindos da riqueza do 
petróleo, em virtude de não contarem com uma indústria nacional fortemente estabelecida quando o início da exploração ocorreu, bem como com instituições capazes de fazer frente às pressões exercidas pelas grandes companhias internacionais de petróleo.

Quanto à experiência latino-americana, merece destaque o caso da Venezuela, dada a anterioridade da exploração de petróleo em seu território. O país teve o primeiro poço comercial descoberto em 1914, e, a partir daí, as companhias estrangeiras comandaram a exploração do petróleo e transformaram a Venezuela no maior exportador mundial de petróleo cru entre 1928 e 1970 (SOUZA, 2008). Em consequência, a Venezuela sofreu uma profunda mudança em sua economia,passando de fundamentalmente agrícola para uma economia gerida pelo petróleo.

Nas décadas de 1920 e 1930, foram promulgadas leis com o intuito de aumentar a apropriação estatal das rendas petrolíferas; na década de 1940, foi determinado um imposto prevendo a divisão igualitária dos lucros da exploração petrolífera entre o Estado e as companhias estrangeiras - conhecido como fiftyfifty -, que vigorou até 1959, quando foi rompido e o Estado passou a ficar com parcelas maiores, preparando o caminho para a estatização da indústria petrolífera e a criação, em 1976, da Petróleos da Venezuela (PDVSA) - companhia estatal de petróleo - com o propósito de extrair petróleo e comandar o processo de crescimento econômico do país (SOUZA; SOUZA; ALVIM, 2008).

Furtado ([1957] 2008), ao analisar o desenvolvimento da economia venezuelana, no período de 1945 a 1956, destacou que era a economia subdesenvolvida de mais alto nível de produto per capita existente naquele período e que tal fato se deu em função da velocidade com que se expandiu o setor petrolífero e a forma como impulsionou o conjunto da economia (FURTADO, [1957] 2008).

O mesmo autor apresenta ainda fatos relevantes para ilustrar a estrutura da economia venezuelana no período estudado: baixíssima participação da agropecuária no produto venezuelano, porém mantendo-se como o setor de maior concentração de trabalhadores; redução da participação da agropecuária e da indústria no conjunto da produção de bens; substituição de artigos de produção interna por produtos importados, tendo como consequência o aumento da vulnerabilidade externa; e aumento da renda ocorrendo de forma concentrada e o consumo das massas populares mantendo-se baixo. Desse 
modo, o dinamismo da economia venezuelana ocorreu em função do valor das exportações que retornavam ao país, graças ao elevado volume das exportações, calculado pelo montante de dólares que as petroleiras vendiam ao Banco Central da Venezuela (FURTADO, [1957] 2008).

Assim, o desenvolvimento venezuelano apresentou características denominadas por Furtado ([1957] 2008), em seu relatório produzido para a Cepal em 1957, de "peculiaridades", pois:

[...] na quase totalidade das economias latino-americanas os problemas mais fundamentais são a escassez relativa de capital e a reduzida capacidade para importar. [...] $\mathrm{Na}$ Venezuela a situação é praticamente oposta: o sistema tende a afogar-se em excesso da capacidade para importar e de recursos financeiros (FURTADO, [1957] 2008, p.56).

As referidas "peculiaridades" mais tarde ficaram conhecidas na literatura como "doença holandesa" e se intensificaram com a majoração do preço do petróleo, ocorrido na década de 1970, acompanhada pela captação de fluxos financeiros em grande quantidade (MEDEIROS, 2008). Ao adentrar a década de 1980, houve queda nos preços do petróleo, a Venezuela "entrou em profunda crise econômica e política, agravada por uma sucessão de governos corruptos" (SOUZA; SOUZA; ALVIM, 2008, p. 74). A estagnação econômica mundial, que teve início nos anos 1980, favorecendo a ascensão de políticas neoliberais voltadas à diminuição da participação do Estado na economia e à abertura de mercados, provoca, na América Latina, igualmente, um longo período recessivo.

Quando Hugo Chávez assumiu o governo, em 1999, o setor agropecuário havia se restringido a tal ponto que a Venezuela dependia da importação de alimentos para abastecer o mercado interno, e os preços do petróleo estavam em um patamar muito baixo. Assim, para impulsionar a economia, ele efetivou mudanças constitucionais e programas econômicos e sociais, com o intuito de afastar-se do modelo rentista, improdutivo e importador, calcado na renda petrolífera (SOUZA; SOUZA, 2009).

Contudo, o estudo de Souza e Souza (2009) mostra que a economia da Venezuela permaneceu excessivamente dependente das receitas do petróleo, ficando exposta às flutuações dos preços internacionais do mesmo. Quando há elevação de preços, o governo adota políticas expansionistas; quando há queda de preços, ocorre a retração dos gastos públicos, perpetuando a ausência de uma política voltada à diversificação produtiva (MEDEIROS, 2008; SOUZA; SOUZA, 2009). Como consequência, na atualidade, a Venezuela passa por uma grave crise econômica e social sem precedentes em sua história. 


\subsection{E QUANTO AO BRASIL?}

No contexto brasileiro, compete ao Conselho Nacional de Política Energética (CNPE) “induzir o incremento dos índices mínimos de conteúdo local de bens e serviços, a serem observados em licitações e contratos de concessão e de partilha de produção" (BRASIL, 2010, p. 2). À ANP, cabe incluir tais índices ao elaborar os editais que regem as licitações para a concessão de exploração, desenvolvimento e produção, bem como garantir que os mesmos estejam previstos nos contratos celebrados e fiscalizar a sua execução, entre outras ações.

O compromisso com o CL esteve presente desde a $1^{\text {a }}$ Rodada de Concessão de Blocos Exploratórios, em 1999, contudo, não foi estipulado um índice de CL mínimo; o compromisso com aquisição local de bens e serviços compôs os critérios de julgamento das ofertas, tendo havido poucas mudanças durante as quatro primeiras rodadas. A partir da 5 Rodada de Concessão de Blocos Exploratórios, em 2003, entretanto, os editais passaram a exigir percentuais mínimos de CL, além de manter o compromisso com aquisição local de bens e serviços como critério de julgamento das ofertas e a previsão de multas no caso de descumprimento dos compromissos. As exigências aumentaram a partir da 7a Rodada de Concessão de Blocos Exploratórios, em 2005, e foram determinados percentuais mínimos e máximos de CL, além de previstos índices diferenciados para blocos situados em águas profundas, águas rasas e em terra ${ }^{3}$.

Todavia, a partir do segundo semestre de 2014, a indústria de petróleo brasileira passou a sofrer as consequências advindas de mudanças ocorridas no cenário internacional - a expansão das fontes de energia renováveis, o aumento das pressões ambientais e o surgimento de novos players na indústria de P\&G -, além de grave crise política e institucional ocorrida no país. Tais fatos acirraram as pressões para as mudanças nas regras da PCL, tendo prevalecido as articulações para reduzir tais percentuais.

Como consequência, houve redução média de 50\% nos compromissos de CL a partir das rodadas de licitação realizadas em 2017; passou a ser adotado um índice de CL único, sem distinção entre bens e serviços, o que pode permitir o cumprimento dos compromissos apenas com serviços, sem a compra de máquinas e equipamentos nacionais; o CNPE aprovou a proposta que permite à ANP reduzir o percentual de CL de contratos já assinados a partir da 7 ${ }^{a}$ Rodada, ocorrida em 2005; foi também sancionada a Lei n⿳ำ 13.586/2017 (BRASIL, 2017), que estabelece novas medidas tributárias para as atividades de exploração e

Para maiores informações, consultar Piquet e Lumbreras (2018). 
produção de P\&G e estende o prazo de vigência do REPETRO 4 de 2018 para 2040. Neste mesmo sentido, há projetos de lei em tramitação na Câmara dos Deputados Federais visando fixar índices de CL, retirando tal atribuição do CNPE (PIQUET; LUMBRERAS, 2018).

Deste modo, o Brasil, sendo um país em desenvolvimento, também tem sofrido pressões para suavizar a PCL, e sua regulamentação tem sido contestada pelas petroleiras - atualmente incluindo a companhia brasileira, Petrobras alegando que devem ser priorizados os segmentos estratégicos da cadeia de suprimentos com maior probabilidade de desenvolvimento e defendendo a criação de um "conteúdo local único" com percentual mais brando. Justificam que tais medidas são necessárias para destravar investimentos e estimular a competição na licitação (PIQUET; LUMBRERAS, 2018).

Por seu turno, a indústria fornecedora e as entidades de classe alegam que, com as mudanças em tela, a indústria naval brasileira entrará em decadência, o país voltará a ser receptor de produtos fabricados no estrangeiro, a geração de empregos e a capacidade de produção serão comprometidas e haverá um retrocesso nas conquistas relativas à inovação (PIQUET; LUMBRERAS, 2018).

A prevalecer a atual tendência da política nacional geral e, particularmente, da política industrial, o país caminha para se tornar um mero exportador de matéria-prima, visto que, além das mudanças relacionadas à regulação da E\&P, a Petrobras tem implantado um acirrado plano de desinvestimentos, dentro do qual já se desfez de sua participação $(90 \%)$ na rede de gasodutos Nova Transportadora do Sudeste (NTS), de sua participação (66\%) no campo de Carcará, da Petrobras Chile Distribuición, de sua participação (67,19\%) na Petrobras Argentina S.A., de sua participação (49\%) na empresa Gaspetro, do campo de Azulão, dos ativos exploratórios na bacia Austral (Argentina), da refinaria de Nansei (Japão), da Empresa de Etanol e Açúcar Guarani, de sua participação (25\%) no campo Roncador, e ainda abriu o capital de 30\% das ações da BR Distribuidora (ALMEIDA; RIBEIRO, 2018).

Ademais, seu Plano de Negócios e Gestão 2018-2020 prevê se desfazer de 70 campos de exploração de petróleo terrestres e 31 campos de águas rasas; de gasodutos nas regiões Norte e Nordeste; da distribuição no Paraguai; das

\footnotetext{
4 Regime aduaneiro especial, que admite a importação de equipamentos específicos a serem empregados diretamente nas atividades de pesquisa e lavra de jazidas de P\&G natural, sem a incidência de tributos federais: II, IPI, PIS e COFINS, bem como do Adicional de Frete para Renovação da Marinha Mercante (AFRMM), criado em 1999 com o intuito de abastecer a cadeia produtiva de $P \& G$ enquanto a indústria nacional se capacitava para atender às demandas da mesma, com previsão inicial de término de vigência em janeiro de 2018.
} 
unidades de fertilizantes; dos ativos na África; e da participação no setor de biodiesel (PETROBRAS, 2018).

Desta feita, o Brasil caminha para um retrocesso em sua política de petróleo e gás a partir do momento em que a Petrobras restringe sua atuação e deixa de ser uma companhia integrada do "poço ao posto", pois, quando se realizam investimentos em E\&P, contando apenas com a importação de bens e serviços, um imenso potencial interno de geração de riqueza é desperdiçado.

\section{CONSIDERAÇÕES FINAIS}

O presente estudo procurou demonstrar que, independentemente do grau de desenvolvimento econômico, os países procuramimplantar políticas industriais com o intuito de fortalecer as empresas localizadas em seu próprio território de modo a contribuir para o desenvolvimento nacional. Contudo, a estratégia utilizada para a adoção das mesmas varia de acordo com a maturidade da indústria, com o estágio de desenvolvimento do país, bem como com o poder de negociação das empresas e dos governos.

Privilegiou-se a análise da política industrial vertical, conhecida como PCL, aplicada ao setor de P\&G. Observa-se que a mesma é adotada por todos os países detentores de reservas,procurando não se limitar exclusivamente à extração e à exportação de óleo bruto, mas simapropriar-se da riqueza proporcionada pela cadeia produtiva quetal recurso é capaz de desencadear. Entretanto, fatores, tais como a maturidade da indústria, a solidez das instituições de apoio, a capacidade de regulação,o monitoramento do Estado e a mobilização dos agentes públicos e privados, interferem nos resultados obtidos.

No Brasil, a adoção de uma política voltada à capacitação de recursos humanos, à consolidação do conglomerado da Petrobras e ao desenvolvimento de empresas fornecedoras nacionais na cadeia produtiva do petróleo - notadamente por meio da PCL - ocorre em conformidade com os princípios de autores, tais como Furtado ([1957] 2008) e Hirschman (1961, 2008), pois visa à consolidação de políticas setoriais de substituição de importações com o intuito de diminuir a dependência do país em relação a produtos e empresas estrangeiras, desenvolver o mercado doméstico e fomentar investimentos em projetos e indústrias que resultem em efeitos em cadeia retrospectivos e prospectivos, podendo estimular o desenvolvimento, bem como evitar a "maldição dos recursos naturais" e a "doença holandesa".

As informações que embasam este artigo fazem parte de uma pesquisa inédita, mais abrangente, que analisou o posicionamento dos atores envolvidos no 
processo de construção da PCL brasileira - petroleiras, empresas fornecedoras e entidades de classe -, destacando que nas negociações para redução de percentuais de CL prevaleceram os argumentos das petroleiras que, além de desqualificarem a indústria local, alegaram ser necessário explorar o petróleo situado nas reservas do pré-sal antes que se consolide a mudança na matriz energética mundial, e o petróleo seja preterido em prol de fontes renováveis.

Aproximadamente uma década após a descoberta do pré-sal, e diante da possibilidade de se tornar uma das maiores produtoras mundiais de petróleo, a Petrobras abdica de seu papel indutor do desenvolvimento do setor,volta-se tão somente ao mercado e à obtenção de lucro aos acionistas e vem se desfazendo de ativos que compõem a cadeia produtiva de P\&G.

Deste modo, apoiando-se nos estudos de Bresser-Pereira, Marconi e Oreiro (2016), pode-se inferir que o Brasil tende a ter dificuldades em neutralizar os efeitos da doença holandesa, ao tornar-se um mero exportador de petróleo bruto de baixo valor agregado, pois será mais difícil equalizar o preço do petróleo ao preço das demais mercadorias. Lembrando que meros exportadores de P\&G não participam ativamente do jogo, são apenas peças nas mãos daqueles que comandam verdadeiramente o jogo.

Por trás da discussão sobre conteúdo local, percebe-se a necessidade de revisão do ambiente de negócios brasileiro, um ambiente carente do estabelecimento de políticas de Estado, e não a de políticas de governo que oscilam conforme os interesses/ideologias daqueles que assumem o poder e não se comprometem com o desenvolvimento da nação. Isso demonstra que, no Brasil, inexiste um projeto de desenvolvimento nacional, e que as questões da energia e do petróleo do pré-sal estão inclusas na agenda neoconservadora, escolhendo a especialização regressiva, a oferta de commodities de baixo valor agregado e a exploração de recursos naturais (BRANDÃO, 2017).

Retomando a pergunta que intitula o artigo, cabe questionar se a riqueza movida a petróleo será maldição ou alavanca para o desenvolvimento brasileiro. Diante dos fatos aqui relatados, acredita-se que o Brasil caminha para o abandono do desenvolvimento sustentável em médio e longo prazo.

\section{REFERÊNCIAS}

ALMEIDA, E.; RIBEIRO, F. A. Impactos da restruturação da Petrobras. In: PIQUET, R.; PINTO JÚNIOR, H. Q. (org.). Transformações em curso na indústria petrolífera brasileira. Rio de Janeiro: Editora E-papers, 2018. p.37-58. 
ANP. A retomada do setor de petróleo e gás. ANP: Rio de Janeiro, 2017.

BACELAR, T.A máquina da desigualdade. Le Monde Diplomatique Brasil, São Paulo, 8 nov. 2007. Ontem e hoje. Disponível em: https://diplomatique.org. br/a-maquina-da-desigualdade/. Acesso em: 27 nov. 2018.

BRANDÃO, C. A. Crise e rodadas de neoliberalização: impactos nos espaços metropolitanos e no mundo do trabalho no Brasil. Cadernos Metrópole, São Paulo, v. 19, n. 38, p. 45-69, abr. 2017.

BRASIL. Emenda Constitucional no 6.15 de agosto de 1995. DOU de 16.8.1995.

BRASIL. Lei $\mathbf{n}^{-}$12.351, de 22 de dezembro de 2010.DOU de 23.12.2010. Dispõe sobre a exploração e a produção de petróleo, de gás natural e de outros hidrocarbonetos fluidos, sob o regime de partilha de produção, em áreas do présal e em áreas estratégicas[...]. Brasília, DF: Presidência da República, [2010]. Disponível em: http://www.planalto.gov.br/ccivil_03/_Ato2007-2010/2010/ Lei/L12351.htm. Acesso em: 27 nov. 2018.

BRASIL. Lei no $\mathbf{1 3 . 5 8 6}$, de 28 de dezembro de 2017. Dispõe sobre o tratamento tributário das atividades de exploração e de desenvolvimento de campo de petróleo ou de gás natural [...]. Brasília, DF: Presidência da República, [2017]. Disponível em: http://www.planalto.gov.br/ccivil_03/_ato2015-2018/2017/ Lei/L13586.htm. Acesso em: 27 nov. 2018.

BRASIL. Ministério do Planejamento. Sobre o Programa de Aceleração do Crescimento (PAC). PAC, Brasília, DF, 2018. Disponível em: http:/ / pac.gov.br/ sobre-o-pac. Acesso em: 27 nov. 2018.

BRESSER-PEREIRA, L. C.; OREIRO, J. L.; MARCONI, N. A doença holandesa. In: BRESSER-PEREIRA, L. C.; OREIRO, J. L.; MARCONI, N. Macroeconomia desenvolvimentista: teoria e política econômica do novo desenvolvimentismo. Rio de Janeiro, RJ: Campus, 2016. p.67-90.

BRUNNSCHWEILER, C. N. Cursing the blessings? Natural resource abundance, institutions, and economic growth. World Development, [S. l.], Vol. 36, No. 3, p. 399-419. 2008.

CANO, W. A desindustrialização do Brasil. Economia e Sociedade, Campinas, Número especial, p. 831-851, jan. 2012.

CEPAL. Políticas para una visión integrada del desarrollo. In: CEPAL. Cambio estructural para la igualdad: una visión integrada del desarrollo.San Salvador: CEPAL, 2012. p.241-259. 
CORDEN, N. M.; NEARY, J.P. Booming sector and de-industrialization in a small open economy. Economic Journal, [S. l.],No. 92, p. 825-848,1982.

DINIZ, E. O contexto internacional e a retomada do debate sobre desenvolvimento no Brasil contemporâneo (2000/2010). DADOS - Revista de Ciências Sociais, Rio de Janeiro, v. 54, n. 4, p. 493-531, 2011.

ENRÍQUEZ, M. A. R. S. Maldição ou dádiva?: os dilemas do desenvolvimento sustentável a partir de uma base mineira. 2007. 449f. Tese (Doutorado em Desenvolvimento Sustentável) - Centro de Desenvolvimento Sustentável, Universidade de Brasília, Brasília, 2007.

FERRAZ, J. C.; PAULA, G. M.; KUPFER, D. Política industrial. In: KUPFER, D.; HASENCLEVER, L. (org.). Economia industrial: fundamentos teóricos e práticas no Brasil. 2.ed. Rio de Janeiro: Elsevier, 2013. p.313-323.

FURTADO, C. O desenvolvimento recente da economia venezuelana. In: FURTADO, C. Ensaios sobre a Venezuela: subdesenvolvimento com abundância de divisas. Rio de Janeiro, Contraponto: CICF, [1957] 2008. p.35-118. HIRSCHMAN, A. O. Estratégia do desenvolvimento econômico. Rio de Janeiro: Editora Fundo de Cultura S. A., 1961.

HIRSCHMAN, A. O. Desenvolvimento por efeitos em cadeia: uma abordagem generalizada. In: SORJ, B.; CARDOSO, F. H.;FONT, M. (org.). Economia e movimentos sociais na América Latina. Rio de Janeiro: Centro Edelstein de Pesquisa Social, 2008. p. 21-64.

KUPFER, D.; FERRAZ, J. C.; MARQUES, F. The return of industrial policy in Brazil. In: STIGLITZ, J. (org.). The industrial policy revolution I: the role of government beyond ideology. Londres: Palgrave, 2013. p. 327-339.

LIN, J. Y.; MONGA, C. Comparative advantage: the silver bullet of industrial policy. In: STIGLITZ, J. (org.). The industrial policy revolution I: the role of government beyond ideology.Londres: Palgrave, 2013. p. 19-38.

LOURENÇO, A. L. C.; CARDOSO, F. A. Crescimento econômico, padrões de especialização e industrialização: um estudo comparativo das exportações do BRIC. Novos Cadernos NAEA, Belém,v. 21, n. 1, p. 9-33,jan./abr. 2018.

MEDEIROS, C. A. Celso Furtado na Venezuela.In: FURTADO, C. Ensaios sobre a Venezuela: subdesenvolvimento com abundância de divisas.Rio de Janeiro: Contraponto: CICF, 2008. p.137-156. 
NILSEN, T.Why Arctic policies matter: the role of exogenous actions in oil and gas industry development in the Norwegian High North. Energy Research \& Social Science, [S.l.], n. 16, p. 45-53,2016.

OVADIA, J. S. Local content policies and petro-development in Sub-Saharan Africa: A comparative analysis. Resources Policy, [S. l.], n. 49, p.20-30, 2016.

PETROBRAS. Plano de negócios e gestão: 2018-2022. Brasília, DF: Petrobras, 2018.

PINTO JÚNIOR, H. Q. O novo contexto do mercadointernacionaldo petróleo e seus impactos para o Brasil. Boletim Petróleo, Royalties e Região, Campos dos Goytacazes, ano XIII, n. 50, p.5-8, 2015.

PINTO JÚNIOR, H. Q. et al. Economia da energia: fundamentos econômicos, evolução histórica e organização industrial. Rio de Janeiro: Elsevier, 2016.

PIQUET, R.; LUMBRERAS, M. J. Política de Conteúdo Local do setor petrolífero brasileiro: uma análise dos interesses em jogo. In: PIQUET, R.; PINTO JÚNIOR, H. Q. Transformações em curso na indústria petrolífera brasileira. Rio de Janeiro: Editora E-papers, 2018. p. 83-125.

POMPERMAYER, F. M. Modelo norueguês de desenvolvimento da cadeia de fornecedores da indústria do petróleo e sua aplicabilidade ao Brasil. Radar, Brasília, DF, n. 17, p. 21-25, 2011.

RIBEIRO, C. G.; NOVAES, H. T. Da "Lei do Petróleo" ao leilão de libra: Petrobras de FHC a Dilma. Revista da Sociedade Brasileira de Economia Política, Niterói, n. 39, p. 34-58, out. 2014.

SACHS, J. D.; WARNER, A. M. Natural resource abundance and economic growth. NBER Working Paper, [S. l.], No. 5398, p. 1-47, Dec. 1995.

SCHUTTE, G. R. Petrobras em marcha forçada. Textos para Discussão, Rio de Janeiro, n. 01, p. 5-96, abr. 2016.

SEMYKINA I. O. Managing regional economic development through Local Content Requirements in oil and gas industry. Ekonomikaregiona [Economy of Region], [S. l.], v. 13, n. 2, p. 457-464,2017.

SOUZA, R. B. L. O desenvolvimento econômico da Venezuela, 1950/2006. 2008. 161f. Tese (Doutorado em Economia do Desenvolvimento) - Faculdade de Ciências Econômicas, Universidade Federal do Rio Grande do Sul, Porto Alegre, 2008. 
SOUZA, R. B. L.; SOUZA, N. J. Análise de indicadores econômicos e sociais da Venezuela, 1999/2008. Revista de Desenvolvimento Econômico, São Paulo, ano XI, n. 20, p.30-40. 2009.

SOUZA, R. B. L.; SOUZA, N. J.; ALVIM, A. M. Fatores do crescimento econômico da Venezuela, 1950/1998. Revista Análise Econômica, São Paulo, ano 26, n. 49, p. 65-86. 2008.

STIGLITZ, J. E.; LIN, J. Y.; MONGA, C. Introduction: the rejuvenation of industrial policy. In: STIGLITZ, J. (org.). The industrial policy revolution I: the role of government beyond ideology. Londres: Palgrave, 2013.p. 1-15.

TORDO, S. et al. (org.). A world bank study. Washington:The World Bank, 2013.

XAVIER JÚNIOR, C. E. R. Políticas de conteúdo local no setor de petróleo: o caso brasileiro e a experiência internacional. Texto para Discussão, Rio de Janeiro, n. 1775, p. 7-33, out. 2012. 